


\title{
CONCURSOS DE ARQUITETURA: AS DIVERGÊNCIAS ENTRE A QUALIDADE DO TRABALHO E A BANALIZAÇÃO DA CULTURA ARQUITETÔNICA
}

\author{
ARCHITECTURE COMPETITIONS: THE DIFFERENCES BETWEENTHE \\ QUALITY OF WORK ANDTHE TRIVIALIZATION OF ARCHITECTURAL \\ CULTURE
}

CONCURSO DE AROUITECTURA: LAS DIFERENCIAS ENTRE LA CALIDAD DEL TRABAJOY LA BANALIZACIÓN DE LA CULTURA AROUITETÓNICA

Taynara Vieira Deiró ${ }^{1}$

\section{Resumo}

O objetivo deste ensaio é refletir sobre os concursos de arquitetura, no intuito de identificar a capacidade desse expediente de causar grandes impactos no meio urbano e discutir a qualidade dos pareceres e a possibilidade da participação popular no júri. Para isso será utilizada como fonte de análise a relação do Brasil com essa prática e a recente transformação da cidade colombiana de Medellin.

Palavras-chave: Concursos de Arquitetura. Medellín. Concursos e o Meio Ambiente. Brasil.

\begin{abstract}
This article aims to reflect upon the architecture contests trying to identify the capability of this expedient in causing huge impacts in the urban area and discuss the quality of reports along the possibility of popular participation in court. To achieve this objective it will be used as source of analysis the relation of Brazil with this exercise and the recent transformation of the Colombian city, Medellin.
\end{abstract}

Keywords: Architectural Contents. Medellín.Contents and the Urban Environment. Brazil.

\footnotetext{
Resumen

El propósito de este ensayo es reflexionar sobre los concursos de arquitectura, con el fin de identificar la capacidad de este dispositivo de causar grandes impactos en las zonas urbanas y discutir la calidad de los dictámenes y la posibilidad de participación popular en el jurado. Para lograr este objetivo se utilizará como fuente de análisis la relación de Brasil con este ejercicio y la reciente transformación de la ciudad colombiana, Medellín.

Palabras clave: Concursos de Arquitectura. Medellin. Concursos y la Calidad de las Ciudads. Brazil.
} 


\section{Introdução}

De acordo com André Pachioni Baeta $(2014)^{2}$, concurso é um tipo de licitação ${ }^{3}$ para a escolha de um trabalho, seja técnico, cientifico ou artístico, mediante a instituição de prêmios para os vencedores, conforme os critérios previstos no edital. Em um concurso de arquitetura, os participantes enviam suas propostas em nível preliminar ou anteprojeto, que serão avaliadas por uma comissão técnica julgadora de acordo com os parâmetros estabelecidos no regulamento. Após a escolha, geralmente, o vencedor é premiado e contratado para desenvolver o projeto executivo. É necessário reforçar ainda que todos os critérios acima são determinados pela Lei 8.666/93 (BRASIL, 1993, art. 37), e recomendados pela Organização das Nações Unidas para a Educação, a Ciência e a Cultura (UNESCO) a todos os países membros da ONU (Organização das Nações Unidas). .

\section{Concursos no Brasil}

No Brasil, os concursos de arquitetura geralmente são organizados e divulgados ${ }^{4}$ pelo IAB (Instituto dos Arquitetos do Brasil), mas também há casos em que empresas privadas selecionam alguns arquitetos de seu interesse para que esses profissionais apresentem suas propostas para determinado empreendimento. Nesse último caso, a participação é restrita para o grupo selecionado, entretanto esse não é o tipo de seleção que se pretende analisar neste texto, pois o enfoque deste ensaio será a relação do governo nacional com esses concursos.

A legislação brasileira diz o seguinte:

\begin{abstract}
Ressalvados os casos de inexigibilidade de licitação, os contratos para a prestação de serviços técnicos profissionais especializados deverão, preferencialmente, ser celebrados mediante a realização de concurso, com estipulação prévia de prêmio ou remuneração.(grifo meu) (Lei 8.666/1993, Art. 13, Inciso I).
\end{abstract}

Apesar de a lei indicar a preferência pela realização de concursos de arquitetura para projetos de edifícios públicos em detrimento de qualquer outra forma, tal prática não é cotidiana no Brasil, ainda que tais competições propiciem benefícios como a revelação de novos talentos e oportunidade de grandes obras serem pensadas por arquitetos competentes que oferecerão arquitetura de qualidade estimulada pela vontade de se destacar na competição. Sem mencionar que poder pensar um espaço público é exercitar a cidadania e ter a oportunidade de criar a cidade que se quer.

No ano de 2014, após o projeto vencedor ser selecionado para a nova Sede do BNDES no Rio de Janeiro, outro projeto executivo, que não o do vencedor, foi contratado segundo critérios de menor preço ou pregão $0^{5}$. Entretanto o ideal seria que o vencedor fosse contratado para dar continuidade ao seu projeto até que chegue em nível de execução.
2. www.concursosdeprojeto.org

3. Segundo o Dicionário Aurélio (2000), licitação significa efetuar (a administração pública) seleção de proposta mais vantajosa para fornecimento de bens ou prestação de serviços.

4. http://www.iab.org.br/concursos

5. SOBREIRA, Fabiano. Concursos de Arquitetura: um impasse jurídico. O Tribunal de Contas da União contra a qualidade da arquitetura pública?.2014. Disponível em: <http:// concursosdeprojeto.org/2014/03/16/ concursos_de_arquitetura_um_impasse_ juridico/\#more-23999>. Acesso em: 15 out. 2015 
Casos como o citado anteriormente são um dos fatores que prejudicam o andamento da prática dos concursos na nação brasileira, em que as poucas edições que acontecem não seguem a legislação em sua totalidade, prejudicando os participantes. Esse é um verdadeiro exemplo de quando a corrupção e o interesse comercial sobrepõem aos benefícios de se realizar tal atividade.

Outro fator desestimulante é a falta de pro labore nas competições brasileiras para suprir os gastos envolvidos. Os arquitetos precisam mobilizar seus escritórios e gastar tempo e dinheiro para criar uma proposta de projeto atrativa sem o menor retorno financeiro, o que torna os concursos uma atividade extra, arriscada e um provável investimento de tempo e dinheiro em vão, além de inviabilizar a participação daqueles que não possuem condições financeiras de financiar seu próprio trabalho. Dessa forma, o arquiteto tem sua função desvalorizada por seu próprio Instituto, que não oferece incentivo para que os profissionais possam se aventurar no universo dos concursos.

O que não acontece em países como a França, por exemplo, onde todas as obras públicas devem ser resultado de concurso6: a seleção começa com a análise dos currículos dos interessados em participar da competição, em seguida, os candidatos selecionados recebem seus honorários correspondentes ao desenvolvimento dos estudos preliminares. ${ }^{7}$

Analisando o processo francês, uma ressalva deve ser feita no sentido de que a seleção de participantes por meio da análise curricular restringe a participação de jovens arquitetos sem muita experiência. Portanto, vale a pena apontar que o modelo nacional que oferece oportunidade a todo profissional capacitado é mais justo e pode proporcionar novas ideias e reconhecimento para profissionais ainda em ascensão.

$\mathrm{Na}$ França, o incentivo vai além da valorização do trabalho do arquiteto, pois o país europeu costuma realizar cerca de 1200 concursos anuais, enquanto o Brasil somente 5.

Mesmo esses 5 concursos anuais deixam a desejar em sua função. Como exemplo tem-se a $22^{a}$ edição do concurso Opera Prima - Concurso Nacional de Trabalhos Finais de Graduação em Arquitetura e Urbanismo, edição de 2010, organizado por revistas do ramo e apoiado pelo $I A B$, que busca dar notoriedade aos novos arquitetos que estão adentrando no mercado, por meio da seleção e premiação de trabalhos de conclusão de curso. Apesar da oportunidade de divulgação dos trabalhos desses novos profissionais ainda desconhecidos, as análises técnicas a respeito dos projetos são bastante superficiais e não demonstram o suposto conhecimento técnico dos jurados. Toma-se como exemplo o parecer do júri para um projeto dessa edição do concurso que trata da qualificação urbana em Brumadinho, feito pela ex-aluna da FUMEC em Belo Horizonte, Maria Paz de Moura Castro:

O projeto apresenta um ambiente paisagístico onde planos e objetos surgem como protagonistas. O alagamento periódico da área é resolvido como elevação de planos e há um estudo criterioso da situação local, do programa e dos sistemas construtivos. O PVC é usado de forma criativa como elemento
6. Lei n 85-704/ 12 julho 1985.

7. SOBREIRA, Fabiano. Panorama Concursos na França. 2009. Disponível em: <https://concursosdeprojeto. org/2009/01/27/panorama-concursos-nafranca/>. Acesso em: 17 dez. 2016. 
translúcido, no trabalho com padronagens de aberturas e na impressão sobre superfícies. (GRUNOW, 2010)

Mesmo sendo um dos projetos premiados, não há indicação dos pontos que possam ter sido negligenciados na proposta e nem questões que poderiam ter sido melhor apresentadas, muito menos a apresentação do motivo pelo qual esse projeto não foi o grande vencedor do ano. Esse tipo de análise vai contra a possibilidade de propiciar uma discussão de qualidade a respeito da arquitetura contemporânea, pois as análises superficiais dos avaliadores em nada acrescentam de conhecimento para se iniciar um debate consistente e muito menos propiciam um aprendizado mais amplo aos participantes que apenas ganham em experiência e, talvez, em prêmios.

\section{O caso de Medellín}

Outro exemplo bem-sucedido, além da França, é o da segunda maior cidade da Colômbia, Medellín. Antes famosa por ser a cidade mais violenta e desigual do mundo por conta do seu famoso cartel de drogas, a capital da província de Antioquia agora é exemplo de como a arquitetura e o urbanismo bem planejado podem ter um efeito transformador.

Um dos catalizadores da reforma foi a Lei 80/1993', que determina que todos os projetos de uso público no território colombiano devem ser objeto de concurso de arquitetura, como forma de assegurar a qualidade desses projetos. Em Medellín, ao contrário do que é praticado no Brasil, as obras vencedoras se situam em áreas pobres e de difícil acesso, como forma de propiciar maior igualdade dentro do território, a fim de levar espaços públicos de qualidade para as regiões menos favorecidas da cidade e, com isso, fazer que a população dessas áreas se sinta parte integrante da estrutura urbana.

Apenas durante o mandato de Sergio Farjado (2004-2007) foram construídos em Medellín os Parques Biblioteca España e Leon de Grief (concursos vencidos pela equipe de Giancarlo Mazzanti), o Parque Biblioteca San Javier (concurso vencido por Javier Veras) e o Parque Biblioteca La Quintana (concurso vencido por Ricardo La Rotta Caballero) ${ }^{9}$. Outros concursos importantes foram o do parque linear ao longo da margem do rio Medellín (onde a cidade se desenvolve) e o do parque perimetral, que evidencia os limites de expansão do município. Todos são projetos de espaços públicos de lazer que contam com a intenção de tirar as pessoas de casa e de promover a relação entre os moradores, visando fazer com que a população colombiana perca o antigo medo de frequentar a rua - estratégia que utiliza a arquitetura para reduzir a insegurança e os altos índices de violência.

Para realizar todas as mudanças, a segunda maior cidade colombiana, assim como a capital do país, conta com uma autarquia municipal conhecida como EDU - Empresa de Desarrolo Urbano, que é responsável por dar continuidade aos projetos sem depender ou se deixar influenciar pelo governante que se encontra no poder. Outra instituição importante é a EPM (Empresa de Serviços Públicos da Colômbia), que disponibiliza 4 bilhões
8. COLOMBIA. Lei $n^{\circ} 80$, de 28 de Outubro de 1993. Estatuto General de Contratación de la Administración Pública. Disponível em: < http://www. alcaldiabogota.gov.co/sisjur/normas/ Norma1.jsp?i=304>. Acesso em: $19 \mathrm{abr}$. 2017.

9. GHIONE, Roberto. Transformação social e urbanística em Medellín. 2014. Disponível em: <http://www. vitruvius.com.br/revistas/read/ minhacidade/14.166/5177>. Acesso em: 26 out. 2015 
de dólares em um intervalo de 3 anos para investimento em obras. Tais instituições têm a função de contornar os obstáculos que os concursos encontram na nação brasileira, como os interesses políticos que são capazes de iniciar obras para conquistar eleitores e paralisá-las quando não forem de interesse da administração atual.

Ao contrário do que ocorre no Brasil, em Medellín as propostas dos concursos são expostas em edifícios públicos para que as pessoas com muito (ou nenhum) interesse direto no assunto também possam conhecer os projetos. Dessa forma, a arquitetura é levada para as massas, sendo oferecida às pessoas a possibilidade de discutir as ideias apresentadas, aprender com elas e com isso começar a pensar não só a edificação em questão, mas também levar esse questionamento para os prédios e espaços públicos da cidade. Um povo que conhece e pensa a arquitetura não é só capaz de reivindicar melhores espaços de lazer, mas também começa a criticar o espaço em que vive, gerando assim discussões que possibilitam o desenvolvimento da arquitetura.

Apesar de ser completamente coerente que a banca de jurados dos concursos seja composta por profissionais dos setores envolvidos, também soa sem sentido que a população seja excluída do processo. Mesmo que os técnicos sejam os mais qualificados para analisar e escolher as propostas que melhor materializem a qualidade e distribuição desejada dos espaços, será o povo que irá frequentar essas futuras edificações, já que se tratam de instalações públicas. A arquitetura é feita por arquitetos para não-arquitetos, logo o principal cliente, que no caso é o povo, deveria ter o direito de opinar, por meio de assembleias participativas e durante o processo de escolha do projeto, em como será o espaço que ele irá frequentar. Mesmo que a opinião técnica vença, não é justo tirar-lhe o poder de posicionamento quanto aos espaços urbanos. Sem mencionar que dando essa oportunidade à população, ela poderá ter um ensejo semelhante à citada acima, de vivenciar e discutir a prática arquitetônica.

Com todos os bons exemplos disponíveis, já está mais do que na hora de o Brasil melhorar seu meio urbano por meio de uma arquitetura e urbanismo de qualidade alcançáveis por meio de concursos, que não custam mais caro do que os meios praticados no momento, mas que ao contrário desses, trazem inúmeros benefícios às cidades e aos seus habitantes. Tais concursos não precisam só se restringir aos grandes equipamentos públicos, mas também podem ser aplicados para a escolha de equipamentos menores, como delegacias, praças e mobiliário urbano, como no caso dos pontos de ônibus de Sabino Barroso em Brasília.

O desenho de Sabino Barroso conjuga simplicidade e robustez. É formado por peças concisas, elementos espaciais que servem de abrigo contra a chuva e sol para passageiros, mantendo a permeabilidade visual nos dois sentidos da pista. O revestimento é feito por placas cerâmicas que recebem todo tipo de intervenção: publicidade barata, ofertas de videntes, correções e melhoramento de monografia, excursões para Caldas Novas, 
Dando continuidade à análise dos pareceres dos jurados de concurso, pode-se observar que Carlos Henrique Lima enaltece os pontos positivos do mobiliário de forma mais poética, focando no ponto de vista do usuário, mas ainda assim peca em negligenciar sua inserção no meio urbano de uma cidade como Brasília e não comparar o mobiliário, fruto de um concurso, com os demais encontrados pelas cidades brasileiras que não seguem o mesmo exemplo.

Estender os concursos aos mobiliários urbanos é propiciar uma cidade completa em qualidade, onde todos os dispositivos públicos atendam à demanda da população da melhor forma possível e ainda ajudam na identidade do contexto urbano em que está inserido.

Toma-se como exemplo a iniciativa da prefeitura de São Paulo, que em 2016 propôs um concurso para a criação de mobiliários urbanos $^{10}$ que partem desde quiosque multiuso até bebedouros e famílias de guarda-corpos. Ressalta-se que essa iniciativa não está restrita apenas a estudantes e a profissionais da área de arquitetura, mas também foram levadas em conta as propostas de outras áreas capacitadas para criar esse tipo de equipamento, como engenharia e vertentes do design, o que possibilita um resultado ainda mais rico por conta da multidisciplinariedade.

\section{Conclusão}

Como visto anteriormente, Medellín é uma grande referência quando se discute a validação dos concursos de arquitetura por meio da transformação urbana advinda das competições promovidas pelos órgãos públicos. A segunda maior cidade da Colômbia ainda apresenta um novo ponto a ser considerado, como exemplo,: levar esses importantes equipamentos públicos para as áreas mais periféricas, com intuito de criar uma cidade mais distribuída em questões de infraestrutura e resgatar a já frágil relação da população com a rua.

Outro ponto importante é a questão da qualidade do parecer do júri, que deve ser vista com um olhar mais crítico, pois os atuais julgamentos brasileiros não refletem muito embasamento técnico, deixando os participantes carentes de justificativas mais elaboradas e com bons fundamentos e referências que reforcem as decisões supostamente capacitadas dos jurados. Essa deficiência só reforça a necessidade da participação popular no processo de seleção, que possibilitaria espaços e equipamentos que reflitam a ideia da cidade ideal dos moradores e a disseminação e o enriquecimento da discussão arquitetônica a partir dos mais diversos pontos de vista, sejam eles embasados em conhecimentos técnicos ou pelo olhar destreinado de seus futuros usuários.

Mesmo que o cidadão comum se defina como indiferente à prática arquitetônica e veja o arquiteto como um profissional inacessível, ele vivencia diversos tipos de espaços ao longo de toda a sua vida e detêm, mesmo que de forma imperceptível, seus próprios ideais estéticos. Portanto, a oportunidade de opinar em como seria o espaço que ele frequentará em seu
10. CORTÉS, Luísa. Prefeitura de São Paulo Lança Concurso Público Nacional de Ideias para Mobiliário Urbano da Cidade. 2016. Disponível em: < http:// www.au.pini.com.br/arquiteturaurbanismo/agenda/prefeitura-de-saopaulo-lanca-concurso-publico-nacionalde-ideias-372816-1.aspx>. Acesso em: 18 dez. 2016 
dia a dia ou em como vai ser a fachada do prédio que verá pela janela todos os dias é tentadora. E além de fazer com que o futuro usuário se sinta importante em fazer parte daquela decisão, ele pode descobrir um interesse até então desconhecido pela organização dos espaços e do meio urbano e ainda contribuir com novos pontos de vista baseados em sua experiência de vida única, que poderá enriquecer os conhecimentos dos projetistas envolvidos, seja para o projeto em questão ou para trabalhos futuros.

Quando comparamos o número de concursos promovidos pelo governo federal com demais países, a média brasileira é preocupante. Porém, antes de começar a se preocupar em aumentar o número de concursos anuais para se equiparar a outros países, o Brasil precisa valorizar a cultura arquitetônica e entender que espaços de qualidade contribuem para o bem-estar urbano, e são até capazes de resolver problemas sociais, como já discutido no caso da cidade colombiana.

Outro benefício, em caso de curto prazo, é o desenvolvimento da habilidade de projetar de todos os envolvidos no desenho, já que todo projeto, principalmente de equipamentos públicos que possuem programas mais complexos e grandes escalas, impõem aos arquitetos uma série de desafios inéditos que contribuem para a capacidade de resolução de problemas tão essencial ao profissional da arquitetura. Sua habilidade de projetar também é estimulada por meio da competição com outros profissionais, pois cada participante deseja fazer o meIhor e propor ideias inovadoras para atender às necessidades do programa da forma mais atrativa, econômica e funcional, com o objetivo de ser o vencedor.

Entretanto, enquanto não existir incentivo financeiro para que os concursos sejam uma prática democrática e recorrente no universo dos escritórios de arquitetura, enquanto for negado ao povo o direito de opinar e enquanto o arquiteto for visto apenas como um profissional de elite, permanecerá distante de nossa realidade todos os benefícios que a prática promove, que se materializa, na tão exaltada, pelos urbanistas, cidade de Medellín.

Em trabalhos nos quais a criatividade impera, estabelecer o critério de melhor preço é uma atitude inconsistente, principalmente quando há outra alternativa com benefícios que extrapolam o âmbito do projeto. Levar o menor preço como fator determinante pode não ser a melhor escolha até mesmo fora do território da arquitetura, ainda mais quando a qualidade de vida urbana está envolvida. Portanto, vale ressaltar que todos os fatores citados, como a participação popular, devem ser levados em consideração em detrimento do custo final em um processo de licitação para projetos públicos de arquitetura.

\section{Referências}

BAETA, André Pachioni. As vantagens dos concursos para a contratação de projetos. 2014. Disponível em:<http://concursosdeprojeto.org/2014/12/10/as_vantagens_dos_concur- 
BRASIL. Lei no 8.666, de 21 de junho de 1993. Regulamenta o art.37, inciso XXI, da Constituição Federal, institui normas para licitações e contratados da Administração Pública e dá outras providências. Disponível em: < http://www.planalto.gov.br/ccivil_03/leis/L8666compilado.htm>. Acesso em: 17 dez. 2016

CORTÉS, Luísa. Prefeitura de São Paulo Lança Concurso Público Nacional de Ideias para Mobiliário Urbano da Cidade. 2016. Disponível em: < http://www.au.pini.com.br/arquitetura-urbanismo/agenda/prefeitura-de-sao-paulo-lanca-concurso-publico-nacional-de-ideias-372816-1.aspx>. Acesso em: 18 dez. 2016

GHIONE, Roberto. Transformação social e urbanística em Medellín. Revistas, São Paulo, ano 14, n. 116.07, Vitruvius. 2014. Disponível em:<http://www.vitruvius.com.br/revistas/read/minhacidade/14.166/5177>. Acesso em: 26 out. 2015

GRUNOW, Evelise. Opera Prima 2010. Projetando com PVC. Projeto Design, São Paulo, ed. 366, Arco web. 2010. Disponível em: <http://arcoweb.com.br/projetodesign/especiais/opera-prima-2010-projetando-com-pvc-01-08-2010>. Acesso em: 31 out. 2015.

LIMA, Carlos Henrique de. Outras aventuras do mobiliário. 2012. Disponível em: <http://concursosdeprojeto. org/2012/06/27/outras-aventuras-do-mobiliario/\#more-19372>. Acesso em: 2 nov. 2015

SOBREIRA, Fabiano. Concursos de Arquitetura: um impasse jurídico. O Tribunal de Contas da União contra a qualidade da arquitetura pública?.2014. Disponível em: <http://concursosdeprojeto.org/2014/03/16/concursos_de_arquitetura_um_impasse_juridico/\#more-23999 >. Acesso em: 15 out. 2015

SOBREIRA, Fabiano. Panorama - Concursos na França. 2009. Disponível em: <https://concursosdeprojeto.org/2009/01/27/ panorama-concursos-na-franca/>. Acesso em: 17 dez. 2016

Recebido em 15/02/2016 Aprovado em 16/12/2016 
Cadernos de Arquitetura e Urbanismo, v.23, n.33, 2" sem. 2016 